\title{
EVIDENCIAÇÃO AMBIENTAL: UMA COMPARAÇÃO DO NÍVEL DE EVIDENCIAÇÃO ENTRE OS RELATÓRIOS DE EMPRESAS BRASILEIRAS
}

\section{ENVIRONMENTAL DISCLOSURE: A COMPARISON BETWEEN THE LEVEL OF DISCLOSURE REPORTS OF BRAZILIAN COMPANIES.}

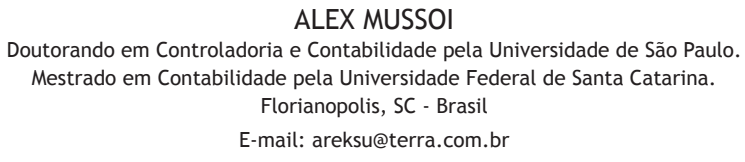

ALEX MUSSOI

Doutorando em Controladoria e Contabilidade pela Universidade de São Paulo. Mestrado em Contabilidade pela Universidade Federal de Santa Catarina. Florianopolis, SC - Brasil

E-mail: areksu@terra.com.br

\author{
HANS MICHAEL VAN BELLEN \\ Professor da Universidade Federal de Santa Catarina, UFSC \\ Doutor em Engenharia de Produção pela Universidade Federal de Santa Catarina. \\ Florianópolis, SC - Brasil \\ E-mail: hansmichael@cse.ufsc.br
}

\section{Resumo}

Com o agravamento da crise ambiental e a ascensão do mercado "verde", a informação ambiental passou a ocupar um lugar de destaque na mídia coorporativa. Gray e Bebbington (2001) afirmam que a performance ambiental refletida nos relatórios empresariais passou a ser um direcionador de investimentos e as empresas que falharem em identificar isso serão penalizadas de maneira econômica e social. Tendo em vista o rumo crescente da evidenciação de informações ambientais, o objetivo principal deste trabalho é identificar em três típos diferentes de relatórios empresariais, o relatório anual (RA), o formulário 20F (20F) e o relatório sócio-ambiental (RSA), quais os tipos de informaçôes ambientais apresentam maior evidenciação, em que nível cada relatório as divulga e qual é o relatório preferido de cada empresa para mostrar suas informações ambientais. O método utilizado foi, predominantemente, quantitativo de cunho descritivo. A amostra selecionada foi de empresas brasileiras que negociam papéis nos mercados brasileiro e dos Estados Unidos. A classificação escolhida para os dados foi adaptada dos trabalhos de Clarkson et al (2008) e Wiseman (1982), com ênfase nos preceitos do Global Reporting Initiative (GRI). Os resultados encontrados comprovam que existem diferenças significativas na quantidade e na qualidade das informações ambientais evidenciadas em cada tipo de relatório. 0 relatório mais completo e com informações mais relevantes é o relatório sócio-ambiental, entretanto, em termos absolutos, o relatório anual é o canal mais utilizado pelas empresas da amostra para divulgar suas informações ambientais e os formulários 20F se destacam na divulgação de informações sobre riscos e litígios ambientais.

Palavras Chave: Evidenciação Ambiental, Contabilidade Ambiental, Relatórios Ambientais, Informações Ambientais

\begin{abstract}
Environmental impact information is becoming increasingly more important in the corporate media. According to Gray and Bebbington (2001), environmental performance has become a driver of investment decisions, and the businesses that fail to identify this feature will be economically and socially penalized. The purpose of this paper is to examine three different types of company reports (the Annual Report "AR", the 2OF Form "2OF", and the Environmental Report "ER"), and to identify the following aspects in these reports: which report discloses the greatest amount of environmental information, what level of disclosure is divulged in each report, and which of these three reports is preferred by the companies when disclosing their environmental information. In addition, a profile with the environmental information will be created for each report. The samples selected were Brazilian companies whose papers are negotiated in both the Brazilian and U.S. markets. The classification chosen for the data was adapted from the works of Clarkson et al (2008) and Wiseman (1982), with emphasis on the Global Reporting Initiative (GRI) precepts. The findings demonstrated that there are significant differences in the quantity and quality of environmental information found in each type of report. The most complete report, and the one with most relevant information, is the Certified Environmental Report, however, the Annual Report is still the one widely used by the sample companies to publish their environmental information and the 2OF report stands out as the one that discloses the most revealing information on risk and environmental disputes.
\end{abstract}

Keywords: Environmental Disclosure, Environmental Accounting, Environmental Reporting, Environmental Information 


\section{INTRODUÇÃO}

Do início da revolução industrial até os dias atuais o planeta Terra sofreu uma rápida transformação. Os recursos naturais, anteriormente abundantes e inesgotáveis, passaram a se tornar escassos e de difícil acesso. Tal racionamento aliado a outros problemas como aquecimento global, contaminação dos solos e dos mananciais, criaram uma grande pressão por uma postura ambientalmente correta da sociedade. As empresas, atores chaves no processo de degradação ambiental, têm um papel relevante a ser cumprido no sentido de preservar o meio ambiente e buscar novas tecnologias sustentáveis. A contabilidade, por sua vez, é uma das responsáveis pela ligação das empresas com a sociedade, ou seja, ela reconhece, mensura e transmite em seus relatórios as informações necessárias para a tomada de decisões de diversos tipos de usuários internos e externos à organização. Apesar da discussão sobre a validade das informações ambientais para o mercado (BELKAOUI 1976; PATTEN 1990; INGRAM 1978; SHANE, SPICER 1983; FREEDMAN, PATTEN 2004; LORRAINE, COLLISON, POWER 2004; MURRAY et al 2006), a demanda por informações ambientais na sociedade vem crescendo como um todo (GRAY, BEBBINGTON 2001).

A contabilidade, mais especificamente a contabilidade ambiental, tem um papel de destaque na organização e na evidenciação das informações relativas ao meio ambiente nos relatórios empresariais. As informações ambientais, apesar da falta de obrigatoriedade de sua evidenciação, já fazem parte do cotidiano das grandes empresas brasileiras. Não evidenciá-las tornou-se uma desvantagem competitiva. Deegan (2004) critica a visão míope das pesquisas que estudam a relação preço açãodivulgação ambiental e defende que as informações ambientais são para uma gama de stakeholders muito maior do que apenas os investidores e os acionistas e, por isso, são fundamentais para a tomada de decisão. Para reforçar essa posição, Deegan e Rankin (1997) apresentaram um artigo no qual foi comprovado estatisticamente, levando-se em conta as limitações de sua amostragem, que a informação ambiental é material para uma série de stakeholders, embora, para os analistas de mercado e para acionistas ela ainda esteja em segundo plano.

No Brasil, os estudos da contabilidade ambiental estão focados, principalmente, na evidenciação dos passivos ambientais e no tratamento contábil dado às externalidades ecológicas (BORBA et al 2006; LIMA, VIEGAS 2001; RIBEIRO, SOUZA 2004; RIBEIRO, MARTINS 1993), contudo, já existem diversos trabalhos que estudam o disclosure ambiental de empresas brasileiras (COSTA, MARION 2007; ROVER, BORBA 2006; NOSSA 2002; CALIXTO, LIMA, BARBOSA 2007).

Internacionalmente, o perfil dos estudos ambientais é diferente. Eles estão mais voltados para verificação do impacto no mercado das informações sócioambientais (LORRAINE, COLLISON, POWER 2004; MURRAY et al 2006; FREEDMAN, PATTEN 2004; BELKAOUI 1976; PATTEN 1990; INGRAM 1978; SHANE, SPICER 1983) e para a comparação entre performance ambiental e o nível de material "verde" evidenciado (INGRAM, FRAZIER 1980; WISEMAN 1982; FREEDMAN, WASLEY 1990; FREEDMAN, JAGGI 1988; HUGHES et al 2001; PATTEN 2002; AL-TUWAIJRI et al 2004; CHO, PATTEN 2007; CLARKSON et al 2008). 
Segundo Epstein e Freedman (1994), uma das maiores dificuldades encontradas por investidores individuais ao analisar as informações ambientais é saber onde localizálas com precisão. Por isso, o objetivo fundamental deste trabalho foi verificar nos três tipos principais de relatórios empresariais divulgados por companhias brasileiras: o relatório anual (RA), o formulário 20F (20F) e o relatório sócio-ambiental (RSA), quais os tipos de informações ambientais que apresentam maior evidenciação, em que nível cada relatório as divulga e qual é o relatório preferido de cada empresa para mostrar as suas informações ambientais. Além disso, foi traçado um perfil da quantidade e do tipo de informação ambiental que é divulgada em cada variedade de relatório analisado.

O artigo subdivide-se em 3 partes: na primeira parte é apresentada uma revisão teórica sobre o papel dos relatórios e das informações ambientais, as formas de evidenciação ambiental e os principais estudos nesse campo de pesquisa, na segunda parte são mostrados os procedimentos metodológicos utilizados na pesquisa e na última parte são apresentados os dados e as conclusões do estudo.

\section{RELATÓRIOS E INFORMAÇÕES AMBIENTAIS}

Os níveis de informações ambientais evidenciadas nos relatórios das companhias vêm crescendo a cada ano. Gray e Bebbington (2001) afirmam que, atualmente, os relatórios ambientais ganharam um espaço importante na mídia corporativa. Apesar disso, tais relatórios ainda são utilizados, quase que exclusivamente, no meio das grandes corporações.

Dentro dos relatórios corporativos as informações ambientais podem exercer diversos papéis diferentes. De acordo com as pesquisas sobre a evidenciação voluntária (CLARKSON et al 2008; DEEGAN, RANKIN 1996), as informações ambientais contidas nos relatórios das companhias, devido ao seu caráter voluntário, prevêem uma associação positiva entre a performance ambiental de uma empresa e o seu nível de evidenciação ambiental discricionária. É importante ressaltar que tal evidência é embasada nos estudos em relatórios não regulamentados e sem obrigatoriedade de publicação. Já as pesquisas fundamentadas nas teorias sócio-políticas, que incluem a teoria da legitimidade, a teoria da política econômica e a teoria do stakeholder, pregam que, quanto maior o nível de evidenciação de informações ambientais, pior é a performance ambiental da empresa (PATTEN 2002; WISEMAN 1982; INGRAM, FRAZIER 1980).

Percebe-se que não existe um consenso sobre a relação desempenho ambiental $x$ quantidade de informações ambientais divulgadas, os estudos passados indicam que a escolha de alguns elementos como a amostra, a classificação dos dados e o tipo de relatório analisado influenciam fortemente os resultados encontrados nas pesquisas.

Na maioria dos países, as informações ambientais ainda são evidenciadas em caráter voluntário, ou seja, não existem regras formais que obriguem as empresas a 
mostrá-las em seus relatórios (com algumas exceções como no caso da Holanda, Suécia e Noruega entre outros). Mesmo assim, a maioria das grandes empresas faz questão de evidenciá-las mesmo incorrendo em um custo de evidenciação (VERRECHIA 1983). Gray e Bebbington (2001) argumentam que as empresas sofrem pressão de uma série de fatores a favor e contrários à evidenciação das informações ambientais. Do lado positivo estão fatores como:

1. legitimar as suas atividades correntes,

2. distrair a atenção da mídia,

3. impacto positivo no preço das ações,

4. vantagem competitiva, e

5. construir uma imagem positiva da organização.

Já do lado negativo estão presentes:

1. os custos diretos e indiretos de evidenciação,

2. a disponibilidade de dados ambientais,

3. a falta de requerimento legal e

4. o foco financeiro das prioridades da empresa.

Além disso, os autores afirmam que os custos políticos também são importantes na determinação do nível de evidenciação voluntária.

Gray e Bebbington (2001) complementam que tais custos podem ser muito pesados e variar muito entre países diferentes, mas, mesmo assim, os benefícios trazidos à empresa pela evidenciação ambiental, como confiança dos stakeholders e moral elevada dos colaboradores, não podem ser desconsiderados na hora de decidir qual a política de transparência deve ser adotada.

Além de fatores de pressão positiva e negativa, a demanda de alguns agentes é fundamental no incentivo dado às entidades para evidenciar informações ambientais. No quadro 1 são apresentados os principais agentes que influenciam a demanda de informações ambientais nas organizações divididos por segmento.

Os motivos reais que levam as empresas a evidenciar suas informações ambientais de maneira voluntária ainda são, em sua maioria, desconhecidos. De acordo com a experiência de Gray e Bebbington (2001), os níveis de evidenciação ambiental nos relatórios de uma firma dependem, principalmente, da sua cultura organizacional.

Tal cultura é refletida por meio das políticas gerais de uma companhia por meio, por exemplo, do reconhecimento da necessidade informacional dos stakeholders e da necessidade de demonstrar parceria social e gerenciamento responsável. 


\section{Principais agentes de influência na evidenciação ambiental de uma organização}

\section{- Negócios e Mercado}

- Pressão de clientes e fornecedores

- Competitividade internacional

- Considerações dos funcionários

- Políticas ambientais

- Relações públicas

- Pressão dos stakeholders

\section{- Pressão Social}

- Crenças pessoais e familiares

- Atenção da mídia

- Escolas e educação

- Stakeholders
- Indústria e iniciativas voluntárias

- Nações Unidas

- Global Reporting Initiative

- Comitês de desenvolvimento

- Associações industriais

- Especificações de cada país

- Eco-labelling

- Prêmios ambientais

- Legislação e Regulamentação

- Liberdade de acesso às informações

- Acordos de impactos ambientais

- Atos e agências de proteção ambiental

- Legislação no sentido da obrigatoriedade da evidenciação

Quadro 1. Agentes de influência da evidenciação ambiental por segmento

Fonte: Adaptado de Gray e Bebbington (2001)

Outro ponto que enseja discussão a respeito dos relatórios ambientais é qual o tipo de informação que será evidenciada. Segundo Gray, Owen e Adams (1996), uma vez que assuntos ambientais são de debates públicos e a comunidade de negócios está cada vez mais se engajando neles, tornou-se difícil para uma companhia de grande porte declarar a sua não intenção de evidenciar informações ambientais.

O reflexo desta problemática impacta diretamente o conteúdo ambiental presente nos relatórios empresariais. Muitas companhias, na busca por uma melhor imagem social, acabam por evidenciar informações menos relevantes ao público, enquanto as informações que, realmente, refletem a performance ambiental, como os indicadores de consumo de recursos e emissão de poluentes, ficam em segundo plano. Além disso, a falta de homogeneidade das informações ambientais presentes nos relatórios restringe a análise a peritos ambientais e dificulta a comparabilidade entre empresas de diferentes setores.

Costa e Marion (2007) identificaram esse problema em seu estudo com companhias do ramo de celulose e papel. Os autores encontraram uma grande dificuldade em analisar as informações ambientais das empresas investigadas e, com isso, identificar as empresas mais comprometidas com a preservação, recuperação e manutenção do meio ambiente. Eles ressaltam que os motivos principais para isso ocorrer são: a falta de uniformidade da apresentação das informações dentro dos relatórios analisados e a prolixidade dos textos que envolvem o meio ambiente. Alguns órgãos, principalmente não governamentais, estão tentando minimizar essa dificuldade.

No quadro 2 é apresentado um modelo incipiente de relatório com informações ambientais que poderiam ser evidenciadas por qualquer empresa. Ele foi adaptado de Gray e Bebbington (2001) e elaborado de acordo com os preceitos do Public 
Environmental Reporting Initiative (PERI) e do Global Reporting Initiative (GRI). 0 $P E R I$ e o GRI são órgãos não-governamentais que têm como atividade principal buscar o aperfeiçoamento da divulgação das informações ambientais e sociais.

\begin{tabular}{|l|}
\hline Diretrizes para evidenciação ambiental \\
\hline 1. Políticas Ambientais \\
\hline 1.1 Declaração de qual é a política ambiental da empresa \\
\hline 1.2 Impactos mais importantes da empresa no meio ambiente \\
\hline 1.3 Passos dados para o monitoramento da compliance com as políticas es tabelecidas \\
\hline 1.4 Declaração de compliance com as políticas estabelecidas \\
\hline 2. Planejamento e Estrutura
\end{tabular}

\section{Planejamento e Estrutura}

2.1 Mudanças estruturais e de responsabilidade realizadas na empresaa fim de desenvolver uma sensibilidade ambiental (criação de um comite/prêmios aos administradores por melhor perfomance ambiental)

2.2 Status do sistema de gestão ambiental (SGA) e seu nível de confiabilidade

2.3 Planos de atividades dentro do (SGA) (introdução ao IPA - indicadores de performance ambiental / auditoria ambiental / critérios de investimentos ambientais)

2.4 Participação dos Stakeholders

\section{Financeiro}

3.1 Gastos com proteção ambiental, com reação ou antecipação da legislação e remediaçao ou melhoramentos pró-ativos

3.2 Traçar o perfil de futuros gastos ambientais - o que é para cumprir a legislação e com o que é volutário e capital/receita divisão

3.3 Contingências, litígios e provisões - impacto na auditoria financeira e impacto nos resultados financeiros

3.4 Detalhes de multas ou notificações ambientais

\section{Atividade}

4.1 Panorama dos recursos utilizados, emissões e desperdícios - em um balanço massificado 4.2 Procedimentos para elaboração do relatório e compliance com os seus padrões.

4.3 Auditoria ambiental e as questões sumárias/resultados

4.4 Indicadores de performance ambiental e trocas entre eles

4.5 Metas e progresso em direção aos direcionadores

4.6 Analise de como a empresa lida com a regulamentação: órgãos/multas/reclamações

4.7 Prêmios/benefícios recebidos

4.8 Análise das atividades de investimento/operações influenciadas por considerações ambientais 4.9 Análise dos projetos volutários que foram realizados

\section{Gerenciamento sustentável}

5.1 Identificação crítica do capital natural sustentável/substituível vrs capital feito pelo homem sobre influência da organização, assim como, as transferências entre as categorias

5.2 Exame das justiças sociais e contas sociais

5.3 Exame de todas as atividades insustentáveis

5.4 Estimativas dos custos sustentáveis

5.5 Ajuste e declaração de entradas/saídas do fluxo de recursos e mudanças entre eles

\section{Atestamento e auditoria}

6.1 Ates tamento dos relatórios ambientais e critérios utilizados neles

6.2 Declaração feita com base no SGA e reconhecimento do seu contexto e suas limitações

Quadro 2. Informações ambientais recomendadas para um relatório ideal Fonte: Adaptado de Gray e Bebbington (2001)

Depois de decidir quais informações serão evidenciadas, o próximo passo é escolher o melhor canal para divulgá-las. Sobre isso, Gray e Bebbington (2001) 
afirmam que a maior parte das informações ambientais são evidenciadas de duas formas:

- Reportadas juntamente com o relatório anual da companhia (ou documento associado) em um espaço separado das informações financeiras tradicionais;

- Reportadas por meio de um relatório exclusivo para tal finalidade, tipicamente publicado separadamente dos demais ou, até mesmo, publicado na Internet.

Os autores complementam que as informações ambientais evidenciadas pelos relatórios anuais tendem a ser mais superficiais. Gray e Bebbington (2001) ressaltam que existe uma forte controvérsia sobre o melhor lugar de serem evidenciadas as informações ambientais. Segundo a sua visão, é fundamental dar uma atenção especial às informações ambientais dentro dos relatórios anuais. As organizações não são apenas entidades econômicas, elas também apresentam um lado social e ambiental e, certamente, geram externalidades que afetam a comunidade como um todo. Demonstrar tais efeitos, conjuntamente com os ganhos econômicos, é primordial para o direcionamento dos investidores.

Apesar de os relatórios anuais serem uma boa fonte geral de informações, os elementos ambientais presentes neles são, frequentemente, insuficientes. Apesar disso, reportar as informações ambientais em relatórios específicos, ainda é quase uma exclusividade das grandes empresas (GRAY, BEBBINGTON 2001). No quadro 3 são apresentadas as vantagens e desvantagens da elaboração de um relatório exclusivamente com informações sócio-ambientais.

\begin{tabular}{|c|c|c|}
\hline Empresa & $\begin{array}{l}\text { Custos Potenciais } \\
\text { - Desenho e formato } \\
\text { - Impressão e distribuição } \\
\text { - Aumento dos Riscos } \\
\text { - Distração de assuntos importantes } \\
\text { - Aumento de ações contra a empresa } \\
\text { - Reações negativas às informações } \\
\text { - Aumento da atenção dos grupos de pressão } \\
\text { - Descrédito } \\
\text { - Perder prestígio na comunidade financeira }\end{array}$ & $\begin{array}{l}\text { Benefícios Potenciais } \\
\text { - Relações públicas } \\
\text { - Encoraja transparência } \\
\text { - Moral aos empregados } \\
\text { - Crença na cultura organizacional } \\
\text { - Direcionamento de assuntos importantes } \\
\text { - Melhora cooperativa } \\
\text { - Melhor relação com os stakeholders } \\
\text { - Educação pública } \\
\text { - Educação aos investidores }\end{array}$ \\
\hline Sociedade & $\begin{array}{l}\text { - Preços maiores } \\
\text { - Menor retorno } \\
\text { - Menor dividendos } \\
\text { - Restrição ao crescimento do negócio } \\
\text { - Desvio de assuntos importantes } \\
\text { - "Cortina de fumaça" } \\
\text { - Informação demasiada }\end{array}$ & $\begin{array}{l}\text { - Aumento da accountability, } \\
\text { transparência e democracia } \\
\text { - Melhor relacionamento com os } \\
\text { negócios } \\
\text { - Escolha sobre conflitos } \\
\text { - Decisões sobre a sustentabilidade } \\
\text { - Um mercado melhor informado }\end{array}$ \\
\hline
\end{tabular}

Quadro 3. Custos e benefícios potenciais da elaboração de um relatório ambiental Fonte: Adaptado de Gray e Bebbington (2001) 


\section{HISTÓRICO DAS PRINCIPAIS PESQUISAS}

Apesar de ser um assunto com grande repercussão atualmente (CLARKSON et al 2008), as primeiras pesquisas envolvendo nível de evidenciação ambiental e performance ambiental das empresas não são recentes. Ingram e Frazier (1980) foram uns dos pioneiros nesse campo de pesquisa ao examinar a relação entre o conteúdo ambiental evidenciado nos relatórios anuais e o desempenho ambiental das empresas pesquisadas. Nessa época os pesquisadores estavam preocupados com a falta de confiabilidade das informações evidenciadas nos relatórios anuais, isso devido à natureza voluntária de tais informações. Os resultados da análise de regressão indicaram que não existe associação entre evidenciação ambiental e performance ambiental nas empresas da amostra. Esse resultado foi consistente com as expectativas dos autores sobre a má qualidade das informações ambientais evidenciadas, principalmente, segundo eles, por serem de características voluntárias.

O próximo trabalho que investigou o tema foi o de Wiseman (1982) que, segundo Clarkson et al (2008), teve um grande impacto no meio acadêmico, tendo em vista que muitos artigos utilizaram seu arcabouço de classificação para os dados ambientais. Em síntese, o trabalho de Wiseman examinou a extensão das evidenciações ambientais voluntárias presentes nos relatórios anuais de algumas companhias estadunidenses. O estudo da autora é focado nas 26 maiores companhias monitoradas pelo Council on Economic Priorities (CEP) entre 1972 e 1976. A grande contribuição de Wiseman foi a criação de um índice que abrange 18 itens separados em 4 categorias: fatores econômicos (5 itens), litígios ambientais ( 2 itens), atividades poluidoras (5 itens) e outras informações ambientais (6 itens). Esse índice foi e ainda é um dos mais utilizados para mensurar o disclosure ambiental das companhias. Já os resultados de sua pesquisa indicaram que não existe uma significativa associação entre o ranking de performance do CEP e o ranking de evidenciação proposto pela autora. As maiores críticas à pesquisa de Wiseman recaem sobre o fato de a pesquisadora ter dado muita ênfase aos dados quantitativos financeiros, colocando um maior peso sobre as consequências financeiras das atividades ambientais.

Já na década de 90, o primeiro trabalho de destaque foi o escrito por Freedman e Wasley (1990). Diferente do trabalho de Freedman e Jaggi (1988), que procurava uma relação entre a evidenciação ambiental e a performance econômica, a proposta de Freedman e Wasley (1990) foi examinar a relação entre o nível de poluição e a sua devida evidenciação nos relatórios anuais e formulários SEC (Securities Exchange Comission) 10 K. O artigo de Freedman e Wasley (1990) é muito similar ao de Wiseman (1982). Os pesquisadores utilizaram as empresas e o ranking do CEP e o mesmo estilo de pesquisa do artigo de 1982. Os resultados também foram similares. A diferença está no relatório analisado, enquanto Wiseman (1982) trabalhou apenas com os relatórios anuais, Freedman e Wasley (1990) acrescentaram os formulários 10K na análise.

Mais recentemente, Hughes, Anderson e Golden (2001) escreveram um artigo avaliando o papel da evidenciação ambiental na determinação da performance ambiental. Apesar de o estudo não ser conclusivo na comparação da evidenciação ambiental com as performances consideradas pelo CEP como boa e média, nas 
empresas classificadas como ruim os dados ambientais são consideravelmente mais evidenciados do que nas outras classificações. Os autores atribuem esse fator ao aumento da regulamentação ambiental exigida pela SEC e pelo FASB (Financial Accounting Standard Board) ocorrida entre os anos de 1992 e 1993. Tais regras teriam forçado as empresas de pior desempenho ambiental a aumentar o seu grau de evidenciação na medida em que elas apresentam um maior custo de remediação ambiental comparado com outras companhias de boa performance ambiental.

No ano seguinte à publicação de Hughes, Anderson e Golden (2001), Patten (2002) escreveu um artigo com pesadas críticas aos trabalhos realizados nesse campo de pesquisa. Segundo o autor, a falta de uma correlação entre performance ambiental e evidenciação ambiental é causada por três grandes motivos:

1. falha no controle de outros fatores associados ao nível de evidenciação ambiental (tamanho da firma e tipo de indústria),

2. amostra inadequada para a pesquisa (em sua maioria, as mesmas empresas controladas pelo CEP), e

3. a utilização de uma medida inadequada de desempenho.

Para superar tais obstáculos, Patten (2002) utilizou uma medida de performance baseada em um ranking publicado pela EPA (Environmental Protection Agency) americana. O ranking utilizava os dados do TRI (Toxics Release Inventory) divididos pela receita para classificar as empresas. Para minimizar os problemas com a seleção da amostra, o pesquisador escolheu, com base nessas informações do TRI/receita de 1988, as 500 maiores empresas do ranking, além disso, as empresas deveriam ter dados com capacidade de serem analisados no sistema COMPUSTAT e ter publicado o relatório anual em 1990. Com base nos pré-requisitos de seleção, a amostra de Patten (2002) ficou composta de 131 empresas de 24 setores. Na parte de classificação de dados, o autor utilizou duas formas de mensuração: a contagem de linhas nos relatórios e uma moldura adaptada de diversos autores da área de evidenciação ambiental como Wiseman (1982), Freedman e Wasley (1990), Deegan e Gordon (1996) e Blacconier e Patten (1994). Os resultados encontrados por Patten (2002) apontam para uma relação positiva entre TRI/receita e as duas formas de mensuração utilizadas pelo autor, sugerindo uma relação negativa entre a quantidade de informações ambientais evidenciadas e a performance ambiental das companhias.

No mesmo caminho de Patten (2002), em 2004 foi publicado o trabalho de Al-Tuwaijri, Christensen e Hughes II (2004). Segundo os autores, o seu trabalho faz uma análise integrada da inter-relação existente entre evidenciação ambiental, performance ambiental e performance econômica utilizando uma abordagem de equação simultânea. Al-Tuwaijri, Christensen e Hughes II (2004) afirmam que após a diferenciação destas três funções corporativas dentro do modelo de equação simultânea eles obtiveram resultados que sugerem que uma boa performance ambiental é significativamente associada a uma boa performance econômica, e, também, associada com uma evidenciação ambiental mais extensiva quantitativamente de medidas e ocorrências específicas de poluição.

Já no ano de 2007, foi publicado o estudo de Cho e Patten (2007). O objetivo 
dos pesquisadores era comprovar o papel da teoria da Legitimidade na evidenciação das informações ambientais. Segundo os autores, a teoria da Legitimidade sugere que as companhias com pior performance ambiental apresentam um maior grau de evidenciação de informações ambientais positivas em seus relatórios financeiros. Os resultados da pesquisa de Cho e Patten (2007) apontam uma variação na utilização da evidenciação por diferentes grupos pesquisados, porém, os resultados gerais dão um suporte adicional ao argumento de que as firmas utilizam as evidenciações ambientais como ferramenta de atingir a legitimidade.

Contrariando os demais estudos, no ano de 2008, foi publicado o trabalho de Clarkson, Li, Richardson e Vasvari (2008). Os autores apontam que o objetivo principal de sua pesquisa é revisar a relação evidenciação/performance ambiental utilizando os preceitos das teorias econômica e social-política de evidenciação voluntárias. Para isso, os autores escolheram um design de pesquisa diferenciado dos demais trabalhos realizados até então. Segundo os pesquisadores, as grandes vantagens de seu trabalho estão na análise apenas de informações discricionárias (não regulamentadas) e na criação de uma tabela classificatória que segue os padrões estabelecidos pelo GRI (Global Reporting Initiative) para sustentabilidade.

Clakson et al (2008) afirmam que esse indexador captura melhor o comprometimento das empresas com o meio ambiente diferentemente dos anteriores baseados em Wiseman (1982). Com base na análise dos relatórios ambientais de uma amostra de 191 empresas dos 5 setores mais poluentes dos Estados Unidos, os autores chegaram à conclusão da existência de uma associação positiva entre performance ambiental e o nível de evidenciação ambiental discricionária. Os pesquisadores complementam que esse resultado é consistente com a teoria econômica de evidenciação e inconsistente com a associação negativa prevista pelas teorias sóciopolíticas.

\section{PROCEDIMENTOS METODOLÓGICOS}

Para atender ao objetivo proposto pelo trabalho, optou-se por uma abordagem, predominantemente, quantitativa, de cunho descritivo, utilizando-se das ferramentas da estatística descritiva para a apresentação e análise dos resultados encontrados.

A amostra foi composta de 28 empresas brasileiras de diversos setores que negociam papéis na BOVESPA e na bolsa de Nova lorque - NYSE. Ela foi escolhida de forma intencional porque empresas que atuam em mais de um mercado possuem uma demanda informacional maior do que empresas que atuam somente no mercado interno. Além disso, são empresas que apresentam um maior nível de acessibilidade dos seus dados. Outro fator que motivou a escolha da amostra foi a possibilidade de comparar as informações ambientais evidenciadas no mercado interno (RA e RSA) com as informações ambientais evidenciadas para o exterior (20F).

Todas as 28 empresas da amostra apresentavam alguma disponibilidade de dados. Os dados foram coletados em três tipos distintos de relatórios: relatório anual 
(mais especificamente o relatório da diretoria) (RA), formulário 20F (20F) e relatório sócio-ambiental (RSA), todos com data de exercício no ano de 2006. Nem todas as empresas da amostra publicam os três relatórios. A tabela 1 apresenta quais são as empresas listadas para a amostra e quais relatórios estavam disponíveis em seus respectivos websites.

Tabela 1 - Empresas Listadas para a amostra

\begin{tabular}{|l|c|c|c|l|l|c|c|c|}
\hline Empresas Listadas para a amostra & \multicolumn{3}{|c|}{ Dados Disponíveis } & Empresas Listadas para a amostra & \multicolumn{2}{c|}{ Dados Disponíveis } \\
\hline Tipo de Relatório & RA & 20F & RSA & Tipo de Relatório & RA & 20F & RSA \\
\hline Ambev & $\mathrm{x}$ & $\mathrm{x}$ & $\mathrm{x}$ & Gol Linhas Aéreas & $\mathrm{x}$ & $\mathrm{x}$ & \\
\hline Aracruz Celulose & $\mathrm{x}$ & $\mathrm{x}$ & & Perdigão & $\mathrm{x}$ & $\mathrm{x}$ & \\
\hline Banco Bradesco & $\mathrm{x}$ & $\mathrm{x}$ & $\mathrm{x}$ & Petrobrás & $\mathrm{x}$ & $\mathrm{x}$ & $\mathrm{x}$ \\
\hline Banco Itau Holding & $\mathrm{x}$ & $\mathrm{x}$ & $\mathrm{x}$ & Sabesp & & $\mathrm{x}$ & \\
\hline Braskem & $\mathrm{x}$ & $\mathrm{x}$ & $\mathrm{x}$ & Sadia & $\mathrm{x}$ & $\mathrm{x}$ & \\
\hline Cemig & $\mathrm{x}$ & $\mathrm{x}$ & $\mathrm{x}$ & Tam & $\mathrm{x}$ & $\mathrm{x}$ & \\
\hline Cia Brasileira de Distribuição & $\mathrm{x}$ & $\mathrm{x}$ & & Telemar & $\mathrm{x}$ & $\mathrm{x}$ & \\
\hline CSN & $\mathrm{x}$ & $\mathrm{x}$ & & Telesp & $\mathrm{x}$ & $\mathrm{x}$ & \\
\hline Companhia Vale do Rio Doce & $\mathrm{x}$ & $\mathrm{x}$ & & Tim & $\mathrm{x}$ & $\mathrm{x}$ & \\
\hline Copel & $\mathrm{x}$ & $\mathrm{x}$ & & Ultrapar Participações & $\mathrm{x}$ & $\mathrm{x}$ & \\
\hline Cosan & $\mathrm{x}$ & & & Unibanco & $\mathrm{x}$ & $\mathrm{x}$ & \\
\hline Cpfl Energia & $\mathrm{x}$ & $\mathrm{x}$ & & Vivo & $\mathrm{x}$ & $\mathrm{x}$ & \\
\hline Embraer & $\mathrm{x}$ & $\mathrm{x}$ & $\mathrm{x}$ & Votorantim Celulose e Papel S.A & $\mathrm{x}$ & $\mathrm{x}$ & $\mathrm{x}$ \\
\hline Gerdau & $\mathrm{x}$ & $\mathrm{x}$ & $\mathrm{x}$ & Brasil Telecom Participações S.A & $\mathrm{x}$ & $\mathrm{x}$ & \\
\hline
\end{tabular}

Para classificação dos dados, foi adaptado dos estudos de Clarkson et al (2008) e de Wiseman (1982) uma tabela classificatória com 2 grupos (aberto e fechado) e 8 subgrupos de informações: (1) estrutura de governança e adaptação do sistema administrativo, (2) credibilidade das políticas ambientais praticadas pela companhia, (3) indicadores ambientais, (4) gastos ambientais, (5) litígio e processos ambientais, (6) visão e estratégia, (7) perfil ambiental e (8) iniciativas ambientais.

A escolha de tal abordagem classificatória foi motivada, principalmente, pela abrangência informacional presente no estudo de Clarkson et al (2008). Segundo os pesquisadores, para montar o seu indexador foram seguidas as orientações de um membro do GRI (Global Reporting Initiative) o que aumentou a credibilidade de sua classificação. Já o estudo de Wiseman (1982), serviu para classificar as informações sobre litígios ambientais (item faltante no estudo de 2008). Além disso, essa classificação aborda itens dos dois tipos de relatórios: voluntários (RSA) e obrigatórios (RA e 20F). Ao todo foram criados e adaptados 60 itens de classificação, sendo que muitos deles constam no modelo ideal de relatório apresentado no Quadro 2.

Para a coleta dos dados ambientais foi escolhido um design de check list, sendo assim, as informações são computadas apenas uma única vez. Dessa maneira, os resultados são medidos pelo número de empresas que apresentam tal informação. $\mathrm{Na}$ apresentação e análise dos dados ambientais, optou-se pela utilização de um índice proporcional de evidenciação baseado na quantidade total do item ambiental coletado dividido pela quantidade total de relatórios daquele tipo analisados. Dessa forma, a classificação representará a proporção de empresas que evidenciaram o item independentemente de quantos relatórios foram analisados. A vantagem desta abordagem é que ela garante que não haja discrepâncias de comparabilidade devido à quantidade diferente dos relatórios. 
Para medir o nível de evidenciação dos relatórios foi montada uma escala baseada no desvio padrão do item em relação à sua média de aparição nos três relatórios. Foram medidos os níveis de evidenciação dos 8 subgrupos de informações ambientais em cada variedade de relatório analisado de acordo com a seguinte escala:

- Nível Bom = índice proporcional de divulgação do item dentro do relatório analisado se encontra em um desvio padrão ou mais acima da média geral de aparição do mesmo item nos três relatórios.

- $\quad$ Nível Normal = índice proporcional de divulgação do item dentro do relatório analisado se encontra próximo da média geral de aparição do mesmo item nos três relatórios.

- $\quad$ Nível Ruim = índice proporcional de divulgação do item dentro do relatório analisado se encontra em um desvio padrão ou mais abaixo da média geral de aparição do mesmo item nos três relatórios ou não foi evidenciado.

Apesar da utilização de uma Proxy já testado para classificar as informações ambientais, existem algumas limitações nesta pesquisa. Segundo Milne e Adler (1998), não existem diferenças entre a confiabilidade desse tipo de instrumento de classificação de dados com outros tipos com contagem de linhas e de palavras. Mas, de acordo com autores, cada um deve ser utilizado para uma finalidade diferente. A classificação por contagem de linhas e palavras é mais indicada para medir a extensão da evidenciação, já o modelo escolhido por essa pesquisa é mais indicado para medir a variedade e a quantidade de informações divulgadas o que constitui o objetivo principal do estudo. Com isso, as características mais qualitativas das informações ambientais não foram analisadas com profundidade neste trabalho.

Além disso, foram excluídas as demonstrações contábeis da análise. 0 motivo desta escolha deve-se, principalmente, às características das informações divulgadas nos demonstrativos contábeis obrigatórios. As informações divulgadas nas demonstrações contábeis obrigatórias apresentam um custo de divulgação maior e são auditadas, isso não ocorre com as demais divulgadas no restante dos relatórios o que acabaria prejudicando a comparabilidade entre elas. Outro fator para não utilização das demonstrações contábeis obrigatórias na análise foi que elas não estão presentes nos RSA o que poderia distorcer os resultados da pesquisa. Outro problema que surge da utilização de uma escala que contempla informações negativas é questão da pertinência da informação.

É necessário ressaltar que mesmo as companhias de atividades semelhantes apresentam diferentes políticas de divulgação para as informações ambientais, principalmente as negativas. Com isso, as companhias que não têm processos ou litígios ambientais poderiam ficar com um nível de evidenciação menor em comparação àquelas que possuem, por outro lado, a não divulgação da informação é um aspecto mais negativo do que evidenciar uma informação ruim (DYE, 1985).

Para contornar este problema, nesta pesquisa foi considerado se a empresa divulgou ou não divulgou a informação, independentemente da sua ocorrência. As 
empresas que divulgam que não possuem informações negativas serão consideradas como aquelas que divulgam possuir litígios ambientais. Assim, as únicas penalizadas serão as que não divulgam nada sobre determinado aspecto, uma vez que todas as informações da escala podem ser pertinentes as atividades das companhias da amostra.

\section{APRESENTAÇÃO E ANÁLISE DOS DADOS}

Foram coletadas e classificadas 799 informações ambientais presentes nos três tipos de relatórios analisados. Nas tabelas 2 e 3 são apresentadas, detalhadamente por quantidade proporcional (quantidade de empresas que divulgam a informação divido pela quantidade de relatórios coletados da amostra), as informações ambientais que foram evidenciadas por tipo de relatório.

$\mathrm{Na}$ tabela 2, foram classificados os itens fechados. Neste grupo foram consideradas as informações com maior poder de comparabilidade entre as empresas, ou seja, informações com características mais quantitativas, que têm maior utilidade na mensuração da performance ambiental das empresas por serem itens mais objetivos. Já na tabela 3 foram indexados os itens abertos. Tais informações possuem uma característica mais qualitativa em comparação às demais, em decorrência disso, elas demonstram melhor a estratégia e a conduta da empresa em relação ao meio ambiente. Juntando os dois tipos de informação se tem um panorama completo do tipo de informações ambientais que deveriam fazer parte do disclosure ambiental das companhias.

Com base na tabela 2 é possível observar alguns aspectos sobre as características da evidenciação ambiental em cada relatório. O RSA possui o maior índice proporcional de itens de performance evidenciados $(15,11)$, além disso, ele apresenta os maiores níveis de divulgação para todos os subgrupos de informações fechadas, com exceção ao item 5 (litígios e processos ambientais), nesta categoria os formulários 20F são o destaque, eles apresentam um índice de evidenciação de $(1,19)$ comparado com $(0,41)$ nos RA e $(0,33)$ nos RSA.

Quanto aos relatórios anuais, eles apresentam um comportamento mediano sem destaque em nenhum dos itens da tabela 2, porém, são mais consistentes em comparação aos formulários 20F. Isso pode ser observado pelo índice geral de divulgação de $(7,52)$ dos RA em comparação ao índice de $(4,11)$ dos Formulários 20F.

A maior diferença entre os subgrupos de informações foi encontrada no item (3) indicadores ambientais. Os indicadores de performance ambiental (consumo de água, emissão de resíduos e etc.) são boas referências de comparabilidade entre as empresas, pois apresentam de forma objetiva o impacto que cada uma delas gera ao meio ambiente. Isso reforça a posição do RSA como melhor relatório para se 
visualizar o desempenho ambiental.

Um aspecto positivo identificado na tabela abaixo é que os relatórios anuais, mesmo bastante atrás dos RSA, apresentam os indicadores ambientais (3) como subgrupo de maior evidenciação $(2,37)$ em relação aos demais (1), (2), (4) e (5), isso sinaliza uma gradual mudança de postura dos administradores que começam a perceber a importância da divulgação dessas informações ambientais juntamente com as informações financeiras.

Tabela 2 - Elementos de evidenciação da performance ambiental

\begin{tabular}{|c|c|c|c|c|c|}
\hline Itens Fechados & RA & $20 \mathrm{~F}$ & RSA & Média & DESVF \\
\hline (1) Estrutura de Governança e Adaptação do siste ma administrativo & 2,30 & 1,19 & 3,22 & 1,84 & 1,02 \\
\hline 1. Existência de um departamento de controle de poluição ou administração de problemas ambientais & 0,15 & 0,07 & 0,33 & 0,13 & 0,13 \\
\hline 2. Existência de um comite de assuntos ambientais na diretoria ou em outro órgão executivo & 0,30 & 0,22 & 0,22 & 0,24 & 0,04 \\
\hline 3. Existência de termos e condições aplicáveis aos fornecedores e/ou clientes sobre práticas ambientais 8 & 0,41 & 0,04 & 0,56 & 0,25 & 0,27 \\
\hline 4. Envolvimento dos Stakeholders na escolha das politicas ambientais praticadas na companhia & 0,26 & 0,04 & 0,22 & 0,15 & 0,12 \\
\hline 5. Implementação da ISO14001 7 & 0,44 & 0,37 & 0,78 & 0,43 & 0,22 \\
\hline 6. Premiação dos executivos atrelada, também, aos indicadores de performance ambiental & 0,04 & 0,00 & 0,11 & 0,03 & 0,06 \\
\hline 7. Existência de código de conduta ou diretrizes ambientais dentro da empresa & 0,30 & 0,15 & 0,56 & 0,25 & 0,21 \\
\hline 8. Sistema de gestão ambiental 9 & 0,41 & 0,30 & 0,44 & 0,34 & 0,08 \\
\hline (2) Credibilidade das Políticas Ambientais & 1,70 & 1,00 & 3,44 & 1,55 & 1,26 \\
\hline 1. Segue orientação de órgão especializado no meio ambiente (GRI) para elaboração dos relatórios & 0,19 & 0,00 & 0,78 & 0,18 & 0,41 \\
\hline 2. Possui auditoria/verificação independente para as informações ambientais dos seus relatórios & 0,11 & 0,07 & 0,22 & 0,10 & 0,08 \\
\hline 3. Possui certificação de programas ambientais ou licenças ambientais emitido por órgão reguladores & 0,26 & 0,44 & 0,44 & 0,34 & 0,11 \\
\hline 4. Os produtos/serviços possuem certificação ambiental emitida por órgão especializado & 0,04 & 0,07 & 0,11 & 0,06 & 0,04 \\
\hline 5. Prêmio de performance ambiental externa ou inclusão em algum indexador ambiental (DSI ou ISE) 6 & 0,56 & 0,11 & 0,56 & 0,34 & 0,26 \\
\hline 6. Envolvimento dos Stakeholders no processo de evidenciação ambiental & 0,00 & 0,00 & 0,44 & 0,06 & 0,26 \\
\hline 7. Participacão em iniciativas voluntárias favoráveis ao meio ambiente reconhecidas por órgãos ambientais & 0,30 & 0,15 & 0,44 & 0,24 & 0,15 \\
\hline 8. Participacão/parceria em associacões ou organizacõos voltadas para a melhoria do meio ambiente & 0,26 & 0,15 & 0,44 & 0,22 & 0,15 \\
\hline (3) Indicadores Ambientais & 2,37 & 0,15 & 6,89 & 1,94 & 3,43 \\
\hline 1. Indicador da utilização/eficiência energética & 0,30 & 0,04 & 0,89 & 0,25 & 0,44 \\
\hline 2. Indicador da utilização/eficiência da água & 0,37 & 0,04 & 0,89 & 0,28 & 0,43 \\
\hline 3. Indicador da emissão de gases do efeito estufa & 0,26 & 0,00 & 0,78 & 0,21 & 0,40 \\
\hline 4. Indicador de emissão de outros gases poluentes & 0,11 & 0,00 & 0,44 & 0,10 & 0,23 \\
\hline 5. Indicador de emissão tóxica (TRI) - Água, Terra e $\mathrm{Ar}$ & 0,07 & 0,00 & 0,11 & 0,04 & 0,06 \\
\hline 6. Indicador de emissão de resíduos sólidos ou líquidos & 0,30 & 0,00 & 0,78 & 0,22 & 0,39 \\
\hline 7. Indicador de reciclagem e aproveitamento dos resíduos & 0,33 & 0,04 & 0,78 & 0,25 & 0,37 \\
\hline 8. Indicador da utilização de recursos não renováveis e conservação da biodiversidade & 0,15 & 0,00 & 0,56 & 0,13 & 0,29 \\
\hline 9. Indicador do impacto dos produtos e serviços no meio ambiente & 0,04 & 0,00 & 0,00 & 0,01 & 0,02 \\
\hline 10. Indicador de compliance na performance ambiental & 0,07 & 0,00 & 0,11 & 0,04 & 0,06 \\
\hline 11. Indicador do uso de recursos materiais totais & 0,15 & 0,00 & 0,56 & 0,13 & 0,29 \\
\hline 12. Indicador do uso de combustíveis (renováveis e Não renováveis) & 0,15 & 0,00 & 0,44 & 0,12 & 0,23 \\
\hline 13. Indicador de derramamento (incidentes) & 0,04 & 0,04 & 0,33 & 0,07 & 0,17 \\
\hline 14. Indicadores do aquecimento global (Neutralização) & 0,04 & 0,00 & 0,22 & 0,04 & 0,12 \\
\hline (4) Gastos Ambientais & 0,74 & 0,59 & 1,22 & 0,70 & $0, \mathbf{3 3}$ \\
\hline 1. Sumário de dinheiro economizado pela companhia com ações de inciativa ambiental & 0,04 & 0,00 & 0,00 & 0,01 & 0,02 \\
\hline 2. Quantia gasta para melhorar a performance ambienta/ecoeficiência ou em projetos ambientais 4 & 0,59 & 0,37 & 0,78 & 0,49 & 0,20 \\
\hline 3. Quantia gasta em multas ou processos ambientais & 0,11 & 0,22 & 0,33 & 0,18 & 0,11 \\
\hline 4. Relação da distribuição dos gastos ambientais & 0,00 & 0,00 & 0,11 & 0,01 & 0,06 \\
\hline (5) Litígios e processos ambientais & 0,41 & 1,19 & 0,33 & 0,69 & 0,47 \\
\hline 1. Processos judiciais ambientais formalizados contra a empresa & 0,11 & 0,30 & 0,11 & 0,18 & 0,11 \\
\hline 2. Autuações e Notificações ambientais recebidas pela empresa & 0,19 & 0,30 & 0,22 & 0,22 & 0,06 \\
\hline 3. Processos ambientais cabíveis contra a empresa & 0,00 & 0,37 & 0,00 & 0,15 & 0,21 \\
\hline 4. Criação de reserva/provisão para contingências am & 0,11 & 0,22 & 0,00 & 0,13 & 0,11 \\
\hline Total Itens de Performance & 7,52 & 4,11 & 15,11 & 8,91 & 5,63 \\
\hline
\end{tabular}

Nos itens de conduta, apresentados na tabela 3, os relatórios sócio-ambientais continuam em primeiro lugar $(7,00)$, porém a diferença com os outros dois relatórios caiu significativamente (desvio padrão geral de 1,40 em comparação com 5,63 da tabela anterior). Os Relatórios Anuais se mantém em segundo $(6,30)$ e os Formulários 
20F em terceiro $(4,30)$.

Tabela - 3 Elementos de evidenciação da conduta ambiental

\begin{tabular}{|c|c|c|c|c|c|}
\hline Itens Abertos & RA & $20 \mathrm{~F}$ & RSA & Média & DESVP \\
\hline (6) Visão e Estratégia & 2,41 & 0,93 & 2,67 & 1,70 & 0,94 \\
\hline 1. Mensagem da diretoria aborda questões ambientais 10 & 0,70 & 0,07 & 0,67 & 0,40 & 0,35 \\
\hline 2. Missão, visão ou valores da companhia aborda a temática ambiental & 0,37 & 0,11 & 0,44 & 0,25 & 0,18 \\
\hline 3. Declaração da empresa sobre o risco de suas atividades ao meio ambiente & 0,07 & 0,26 & 0,00 & 0,13 & 0,13 \\
\hline 4. Declaração da empresa sobre revisões periódicas em sua performance ambiental & 0,04 & 0,00 & 0,00 & 0,01 & 0,02 \\
\hline 5. Declaração da empresa sobre futuros objetivos ambientais a serem atingidos & 0,37 & 0,07 & 0,56 & 0,25 & 0,24 \\
\hline 6. Declaração da empresa sobre inovações ambientais ou novas tecnologias ambientalmente corretas & 0,22 & 0,11 & 0,44 & 0,19 & 0,17 \\
\hline 7. Declaração reafirmando o comprometimento com o meio ambiente através de suas ações sustentáveis 3 & 0,63 & 0,30 & 0,67 & 0,46 & 0,20 \\
\hline (7) Perfil Ambiental & 0,78 & 2,00 & 1,00 & 1,25 & 0,65 \\
\hline 1. Declaração de compliance (ou falta de) com os padrões ambientais de órgãos locais ou internacionais & 0,37 & 0,41 & 0,44 & 0,37 & 0,04 \\
\hline 2. Uma visão geral do impacto da regulamentação ambiental sobre a empresa & 0,07 & 0,70 & 0,00 & 0,31 & 0,39 \\
\hline 3. Uma visão geral de como a atividade ou produto da empresa impacta o meio ambiente & 0,15 & 0,30 & 0,33 & 0,22 & 0,10 \\
\hline 4. Uma visão geral da performance da empresa em relação aos seus concorrentes & 0,04 & 0,00 & 0,22 & 0,04 & 0,12 \\
\hline 5. Fatores de riscos ambientais que podem afetar o desempenho da empresa & 0,15 & 0,59 & 0,00 & 0,30 & 0,31 \\
\hline (8) Iniciativas Ambientais & 3,11 & 1,37 & 3,33 & 2,25 & $\mathbf{1 , 0 7}$ \\
\hline 1. Descrição do treinamento de funcionários em questões ambientais & 0,37 & 0,04 & 0,67 & 0,25 & 0,31 \\
\hline 2. Existência de planos de resposta em casos de acidentes ambientais & 0,07 & 0,22 & 0,22 & 0,15 & 0,09 \\
\hline 3. Prêmios ambientais internos & 0,00 & 0,00 & 0,00 & 0,00 & 0,00 \\
\hline 4. Auditoria ambiental interna & 0,04 & 0,00 & 0,00 & 0,01 & 0,02 \\
\hline 5. Certificações internas de programas ambientais & 0,00 & 0,00 & 0,00 & 0,00 & 0,00 \\
\hline 6. Accões Voltadas à economia e reaproveitamento de recursos naturais 5 & 0,56 & 0,26 & 0,56 & 0,40 & 0,17 \\
\hline 7. Projetos voltados ao meio ambiente em diversas áreas 1 & 0,85 & 0,41 & 0,89 & 0,63 & 0,27 \\
\hline 8. Iniciativas voltadas à redução das emissões de poluentes 2 & 0,67 & 0,33 & 0,56 & 0,48 & 0,17 \\
\hline 9. Conservação da Biodiversidade & 0,26 & 0,07 & 0,22 & 0,16 & 0,10 \\
\hline 10. Coleta seletiva de lixo & 0,30 & 0,04 & 0,22 & 0,16 & 0,13 \\
\hline Total itens de Conduta & 6,30 & 4,30 & 7,00 & 5,86 & 1,40 \\
\hline
\end{tabular}

Novamente os RSA levam vantagem na maioria dos itens com exceção do subgrupo (7) perfil ambiental que é liderado pelos Formulários 20F $(2,00)$. Ao aprofundar a análise em ambas as tabelas, verifica-se que alguns itens são divulgados quase que exclusivamente pelos Formulários 20F (5.1/5.3/6.3/7.2/7.5).

Essas informações apresentam algumas características em comum, sobretudo, elas representam os riscos ambientais das atividades nas empresas e podem influenciar de maneira significativa o resultado financeiro do período. Quanto a isso, cabe ressaltar o papel da Securities Exchange Comission (SEC) como órgão regulador da divulgação de informações no mercado dos Estados Unidos.

As informações evidenciadas pelos Formulários 20F são exigência da SEC, por isso, as empresas brasileiras são obrigadas a divulgá-las sob pena de multa e repreensão do órgão regulador. As demais informações ambientais divulgadas nos outros relatórios são, em sua maioria, de natureza voluntária, ou seja, sem regulamentação que obrigue as empresas a divulgá-las. 
Tabela 4 - Nível de evidenciação das informações ambientais

\begin{tabular}{|l|c|c|c}
\hline Relatórios analisados & RA & $20 F$ & RSA \\
\hline Itens Fechados & & & \\
\hline (1) Estrutura de Governanca e Adaptacão do sistema adminis trativo & Normal & Normal & Bom \\
\hline (2) Cre dibilidade das Políticas Ambientais & Normal & Normal & Bom \\
\hline (3) Indicadores Ambientais & Normal & Ruim & Bom \\
\hline (4) Gas tos Ambientais & Normal & Normal & Bom \\
\hline (5) Litígios e processos ambientais & Normal & Bom & Normal \\
\hline Itens Abertos & & & \\
\hline (6) Visão e Es tratégia & Normal & Normal & Bom \\
\hline (7) Perfil Ambiental & Normal & Bom & Normal \\
\hline (8) Iniciativas Ambientais & Normal & Normal & Bom \\
\hline
\end{tabular}

Na tabela 4 é ilustrado de maneira sintética o nível de evidenciação dos grupos classificatórios. 0 destaque é novamente o RSA que fica acima da média em quase todos os subgrupos de informação. O Formulário 20F apresenta um nível Bom em dois subgrupos no (5) e no (7), curiosamente os únicos subgrupos que apresentam um nível Normal no RSA. Um subgrupo que ficou bem abaixo da média foi o (5) no Formulário 20F, isso representa que esse tipo de relatório não é utilizado para divulgar essa categoria de informação. O RA apresentou um nível de evidenciação próximo da média em todos os tópicos.

Na próxima tabela (5), são demonstrados, de maneira geral, os resultados do estudo. Os dados apontam para uma superioridade do RSA, seguido pelo RA e, por fim, o 20F. Dos 60 itens da classificação os RSA em média apresentaram 22,11 (36,85\%), os RA $13,81(23,01 \%)$ e os Formulários 20F 8,41 (14,01\%). A superioridade dos RSA é confirmada, também, pela maior média por tópico e pela maior média por índice.

Tabela 5 - Total das informações ambientais evidenciadas

\begin{tabular}{|l|c|c|c|c|c|}
\hline Relatórios analis ados & RA & 20F & RSA & Média & DESVP \\
\hline Informacões evidenciadas total & 13,81 & 8,41 & 22,11 & 14,78 & 6,90 \\
\hline Média por tópico & 1,73 & 1,05 & 2,76 & 1,85 & $\mathbf{0 , 8 6}$ \\
\hline Desvio padrão por tópico & $\mathbf{0 , 9 8}$ & $\mathbf{0 , 5 5}$ & $\mathbf{2 , 0 5}$ & 1,19 & $\mathbf{0 , 7 7}$ \\
\hline Média por índice & $\mathbf{0 , 2 3}$ & $\mathbf{0 , 1 4}$ & $\mathbf{0 , 3 7}$ & $\mathbf{0 , 2 5}$ & $\mathbf{0 , 1 2}$ \\
\hline Desvio padrão por índice & $\mathbf{0 , 2 0}$ & $\mathbf{0 , 1 7}$ & $\mathbf{0 , 2 8}$ & $\mathbf{0 , 2 1}$ & $\mathbf{0 , 0 6}$ \\
\hline
\end{tabular}

Além da diferença na quantidade de divulgação que foi detectada em cada tipo de relatório analisado, outro aspecto importante foi verificar os diferentes perfis de informações ambientais evidenciadas em cada tipo de demonstração. As tabelas a seguir apresentam de forma detalhada os 10 tipos de informações ambientais que mais foram evidenciadas por variedade de relatório.

Na tabela 6 é apresentado um ranking com as 10 informações ambientais mais divulgadas nos relatórios anuais. De acordo com Gray e Bebbington (2001), os 
relatórios anuais, em relação aos relatórios sócio-ambientais, apresentam informações ambientais mais superficiais e generalistas. Segundo Epstein e Freedman (1994), Tinoco (1993) e Murray et al (2006), o relatório anual é o meio de comunicação mais utilizado da empresa com seus diversos usuários externos, principalmente, o mercado. Ao analisar as informações ambientais mais evidenciadas pelos relatórios anuais, percebe-se que as informações mais divulgadas pelas empresas da amostra são de natureza abrangente, ou seja, com exceção do $5^{\circ}$ ao $8^{\circ}$ lugares, não são informações que permitem analisar os seus desempenhos ambientais com objetividade.

Tabela 6 - Informações ambientais mais divulgadas nos Relatórios Anuais

\begin{tabular}{|c|c|c|}
\hline Perfil de Informações dos Relatórios Anuais & Índice & Rkg \\
\hline Projetos voltados ao meio ambiente em diversas áreas (item 8.7) & 0,85 & 1 \\
\hline Mensagem da diretoria aborda questões ambientais (item 6.1) & 0,70 & 2 \\
\hline Iniciativas voltadas à redução das emissões de poluentes (item 8.8 ) & 0,67 & 3 \\
\hline Declaração reafirmando o comprometimento com o meio ambiente através de suas ações sustentáveis (item 6.7) & 0,63 & 4 \\
\hline Quantia gasta para melhorar a performance ambiental/ecoeficiência ou em projetos ambientais (item 4.2) & 0,59 & 5 \\
\hline Ações Voltadas à economia e reaproveitamento de recursos naturais (item 8.6) & 0,56 & 6 \\
\hline Prêmio de performance ambiental externa ou inclusão em algum indexador ambiental (DSI ou ISE) (item 2.5) & 0,56 & 6 \\
\hline Implementação da ISO14001 (item 1.5) & 0,44 & 8 \\
\hline Existência de termos e condições aplicáveis aos fornecedores e/ou clientes sobre práticas ambientais (item 1.3) & 0,41 & 9 \\
\hline Sistema de gestão ambiental (item 1.8) & 0,41 & 9 \\
\hline
\end{tabular}

Isso é bem caracterizado pelos 4 primeiros itens mais evidenciados, são todos elementos menos objetivos, ou seja, eles refletem a conduta ambiental da empresa e não servem para mensurar a sua performance ambiental.

Na tabela 7 são demonstradas as informações mais divulgadas pelos formulários 20F. De maneira geral, nota-se que, para as empresas pesquisadas, as informações deste tipo de relatório são bem diferentes dos demais relatórios (RA e RSA).

Tabela 7 - Informações ambientais mais divulgadas nos Formulários 20F

\begin{tabular}{|c|c|c|}
\hline Pefil de Informações dos Formulários 20F & Índice & Rkg \\
\hline Uma visão geral do impacto da regulamentação ambiental sobre a empresa (item 7.2) & 0,70 & 1 \\
\hline Fatores de riscos ambientais que podem afetar o desempenho da empresa (item 7.5) & 0,59 & 2 \\
\hline Possui certificação de programas ambientais ou licenças ambientais emitido por órgão reguladores (item 2.3) & 0,44 & 3 \\
\hline Declaração de compliance (ou falta de) com os padrões ambientais de órgãos locais ou internacionais (item 7.1) & 0,41 & 4 \\
\hline Projetos voltados ao meio ambiente em diversas áreas (item 8.7) & 0,41 & 4 \\
\hline Processos ambientais cabíveis contra a empresa (item 5.3) & 0,37 & 6 \\
\hline Quantia gasta para melhorar a performance ambiental/ecoeficiência ou em projetos ambientais (item 4.2) & 0,37 & 6 \\
\hline Implementação da ISO14001 (item 1.5) & 0,37 & 6 \\
\hline Iniciativas voltadas à redução das emissões de poluentes (item 8.8) & 0,33 & 9 \\
\hline Sistema de gestão ambiental (item 1.8) & 0,30 & 10 \\
\hline Processos judiciais ambientais formalizados contra a empresa (item 5.1) & 0,30 & 10 \\
\hline Autuações e Notificações ambientais recebidas pela empresa (item 5.2) & 0,30 & 10 \\
\hline Declaração reafirmando o comprometimento com o meio ambiente através de suas ações sustentáveis (i & 0,30 & 10 \\
\hline Uma visão geral de como a atividade ou produto da empresa impacta o meio ambiente (item 7.3) & 0,30 & 10 \\
\hline
\end{tabular}

Como já foi dito anteriormente, as informações evidenciadas nos formulários 20F sofrem influência da regulamentação da SEC que obriga as empresas a divulgar qualquer tipo de risco que está sujeito o negócio. As 4 primeiras informações do ranking estão diretamente relacionadas com esse aspecto, ou seja, são divulgadas com o intuito de transparecer os riscos ambientais das atividades realizadas pelas 
empresas. As demais informações do ranking também estão relacionadas aos riscos ambientais, a diferença é que, com exceção das informações sobre litígios, que na amostra aparecem quase que exclusivamente neste tipo de relatório, elas são atitudes ou políticas que as empresas adotam para diminuir o risco ambiental a que estão sujeitas.

Para as empresas da amostra o RSA é o relatório mais completo de informações ambientais. Na tabela 8 é apresentado o ranking com o perfil das informações ambientais divulgadas por este tipo de relatório. Diferentemente das outras duas variedades de relatório, as empresas que publicam o RSA apresentam informações mais objetivas sobre a performance ambiental. Com exceção do item 8.7, os primeiros lugares do ranking (evidenciado por $89 \%$ das empresas que publicam tal relatório) foram indicadores de desempenho ambiental. Isso é um bom sinal, pois é por meio destes indicadores que se pode avaliar o impacto ambiental e a relação empresameio ambiente.

Tabela 8. Informações ambientais mais divulgadas nos relatórios sócio-ambientais

\begin{tabular}{|c|c|c|}
\hline Perfil de Informações dos Relatórios Sócio-Ambientais & Índice & Rkg \\
\hline Indicador da utilização/eficiência energética (item 3.1) & 0,89 & 1 \\
\hline Indicador da utilização/eficiência da água (item 3.2) & 0,89 & 1 \\
\hline Projetos voltados ao meio ambiente em diversas áreas (item 8.7) & 0,89 & 1 \\
\hline Indicador da emissão de gases do efeito estufa (item 3.3) & 0,78 & 4 \\
\hline Indicador de emissão de resíduos sólidos ou líquidos (item 3.6) & 0,78 & 4 \\
\hline Indicador de reciclagem e aproveitamento dos resíduos (item 3.7) & 0,78 & 4 \\
\hline Quantia gasta para melhorar a performance ambiental/ecoeficiência ou em projetos ambientais (item 4.2) & 0,78 & 4 \\
\hline Segue orientação de órgão especializado no meio ambiente (GRI) para elaboração dos relatórios (item 2.1) & 0,78 & 4 \\
\hline Implementação da ISO14001 (item 1.5) & 0,78 & 4 \\
\hline Mensagem da diretoria aborda questões ambientais (item 6.1) & 0,67 & 10 \\
\hline Declaração reafirmando o comprometimento com o meio ambiente através de suas ações sustentáveis (item 6.7) & 0,67 & 10 \\
\hline Descrição do treinamento de funcionários em questões ambientais (item 8.1) & 0,67 & 10 \\
\hline
\end{tabular}

Os demais itens que aparecem na tabela 8 são itens mais genéricos, mas, mesmo assim, são de grande importância, pois demonstram bem as políticas da empresa com o meio ambiente, como é o caso da ISO14001 e se empresa segue as orientações do GRI ou outro padrão de relatório ambiental.

Algumas informações são bem evidenciadas nos três tipos de relatórios como é o caso dos itens 1.5 (implementação da ISO14001), 8.7 (projetos voltados ao meio ambiente em diversas áreas) e 4.2 (quantia gasta para melhorar a performance ambiental/ecoeficiência ou em projetos ambientais). A certificação ISO14001 representa que a empresa segue as normas ambientais estabelecidas por uma certificadora, os projetos ambientais são formas de a empresa preservar o meio ambiente ou ajudar a restabelecê-lo e os gastos para melhorar a performance ambiental são para mitigar o impacto da empresa sobre o meio ambiente. É importante ressaltar que as características destas informações são similares. Elas representam um esforço ou um gasto que a empresa teve em prol do meio ambiente para melhorar a sua imagem perante a sociedade.

Além das diferentes características das informações ambientais presentes nos relatórios analisados, as empresas da amostra também utilizam canais diferentes para divulgar suas informações de natureza ambiental. Na tabela 9 é traçado um 
panorama geral da quantidade de informações ambientais que foram evidenciadas pelas empresas estudadas e o seu local preferido de divulgação. É interessante observar que em alguns casos, empresas de setores considerados de menor impacto ambiental como bancos e telefonia evidenciam mais informações ambientais do que empresas em setores potencialmente poluidores como siderurgia e aviação civil.

Tabela 9. Distribuição das informações ambientais empresa-relatório

\begin{tabular}{|c|c|c|c|c|c|c|c|c|c|}
\hline \multirow{2}{*}{$\begin{array}{l}\text { Empresas Listadas } \\
\text { Tipo de Relatório } \\
\end{array}$} & \multicolumn{3}{|c|}{ Qtd. de Informação Ambiental } & \multirow{2}{*}{ total } & \multirow{2}{*}{\begin{tabular}{|l|} 
Empresas Listadas \\
Tipo de Relatório \\
\end{tabular}} & \multicolumn{3}{|c|}{ Qtd. de Informação Ambiental } & \multirow{2}{*}{ total } \\
\hline & RA & $20 \mathrm{~F}$ & RSA & & & RA & $20 \mathrm{~F}$ & RSA & \\
\hline Ambev & 16 & 4 & 15 & 35 & Gol Linhas Aéreas & 8 & 4 & - & 12 \\
\hline Aracruz Celulose & 30 & 5 & - & 35 & Perdigão & 10 & 19 & - & 29 \\
\hline Banco Bradesco & 6 & 2 & 26 & 34 & Petrobrás & 27 & 26 & 39 & 92 \\
\hline Banco Itau Holding & 8 & 6 & 17 & 31 & Sabesp & - & 17 & - & 17 \\
\hline Braskem & 6 & 14 & 15 & 35 & Sadia & 17 & 8 & - & 25 \\
\hline Cemig & 11 & 19 & 21 & 51 & Tam & 7 & 1 & - & 8 \\
\hline Cia Brasileira de Distribuição & 5 & 3 & - & 8 & Telemar & 12 & 0 & - & 12 \\
\hline $\mathrm{CSN}$ & 11 & 12 & - & 23 & Telesp & 11 & 0 & - & 11 \\
\hline Companhia Vale do Rio Doce & 22 & 18 & - & 40 & Tim & 21 & 0 & - & 21 \\
\hline Copel & 31 & 9 & - & 40 & Ultrapar Participações & 16 & 7 & - & 23 \\
\hline Cosan & 12 & - & - & 12 & Unibanco & 9 & 2 & - & 11 \\
\hline Cpfl Energia & 28 & 10 & - & 38 & Vivo & 6 & 0 & - & 6 \\
\hline Embraer & 5 & 10 & 8 & 23 & Votorantim Celulose e Papel S.A & 1 & 20 & 42 & 63 \\
\hline Gerdau & 24 & 4 & 16 & 44 & Brasil Telecom Participações S.A & 13 & 7 & - & 20 \\
\hline
\end{tabular}

Conforme apresentado na tabela 9, de maneira geral, a empresa que apresentou relatório mais completo foi a Votorantin Celulose e Papel (VCP). O relatório sócioambiental da VCP apresentou 42 informações das 60 disponíveis no indexador, isso representa que a empresa evidenciou $70 \%$ das informações ambientais consideradas ideais (quadro 2) para um relatório ambiental. Em segundo lugar veio o RSA da Petrobrás com 39 informações evidenciadas. Uma curiosidade foi o Banco Bradesco, que apresentou 26 informações das 60 possíveis no seu RSA. 0 Bradesco atua no mercado financeiro e apresentou um nível de evidenciação ambiental melhor do que empresas como a COSAN, CSN e Ultrapar participações que exercem atividades com um maior grau de poluição. Nos relatórios anuais a empresa com maior nível de evidenciação foi a Copel (31 itens) seguida pela Aracruz Celulose (30 itens). Ambas as companhias não publicam relatórios sócio-ambientais. Elas preferem divulgar as suas informações ambientais juntamente com as suas informações financeiras. Nos formulários 20F a empresa destaque foi a Petrobrás com 26 itens evidenciados. Ela ficou bem acima da média geral (8,4 informações ambientais divulgadas).

Apesar de os Relatórios Anuais divulgarem informações com características mais superficiais em comparação com os outros relatórios, de maneira absoluta, ele é o preferido das empresas da amostra com 373 informações ambientais divulgadas. Isso significa que a maioria das empresas pesquisadas ainda não visualizou os benefícios ou a necessidade de se publicar um relatório exclusivo com informações ambientais (RSA). Sobre isso, é importante observar que algumas empresas que não publicam o RSA (Aracruz, Vale, CPFL e Copel) utilizam o RA como principal forma de divulgação de informações ambientais e que as informações ambientais presentes em tais relatórios são mais extensas e objetivas, ou seja, essas empresas apresentam um melhor nível de informações ambientais divulgadas nos relatórios anuais se comparadas com os RA das demais empresas que utilizam os dois relatórios.

É necessário ressaltar que as empresas da amostra apresentam diferentes 
tamanhos e complexidades operacionais, isso aliado a características intrínsecas dos seus setores de atuação podem alterar de maneira significativa a quantidade de informações ambientais divulgadas por elas. Verrecchia (1983), afirma que toda a informação (boa ou ruim) divulgada de forma voluntária apresenta um custo de divulgação que é função do tempo e da especulação do mercado sobre tal informação. 0 administrador divulga uma informação voluntária no momento em que o custo de divulgação se aproxima de zero, ou seja, é necessário que ele visualize a necessidade ou demanda por tal informação, caso contrário, ela não será divulgada. A diferença nas variedades das informações ambientais divulgadas nos relatórios mostra que os administradores de algumas empresas já começaram a identificar o aumento da demanda pela informação ambiental, o que ficou refletido nas suas políticas de disclosure.

\section{CONSIDERAÇÕES FINAIS}

Os resultados encontrados nesta pesquisa apontam que existem diferenças extensas na quantidade e no conteúdo ambiental divulgado nos diferentes tipos de relatórios analisados. Apesar de o relatório sócio-ambiental ser divulgado ainda de forma incipiente pelas empresas da amostra (apenas 32\% das empresas divulgam tal demonstração), ele é o que apresenta melhor desempenho em divulgar informações ambientais, tanto quantitativamente quanto qualitativamente. Já os formulários $20 \mathrm{~F}$ se mostraram as melhores fontes de informações sobre riscos e litígios ambientais.

Grande parte das pesquisas recentes que estudam a relação da variação do preço da empresa no mercado e a quantidade de informações ambientais divulgadas não encontrou uma associação direta entre as variáveis (FREEDMAN, PATTEN 2004; LORRAINE, COLLISON, POWER 2004; MURRAY et al 2006), o que significa que o mercado não é sensível às informações ambientais divulgadas pelas empresas que foram pesquisadas. Essa característica ficou refletida na quantidade e na variedade de informações ambientais que foram divulgadas nos relatórios anuais das empresas escolhidas para a pesquisa. A maioria das informações ambientais divulgadas nos relatórios anuais analisados (com exceção de algumas empresas que atuam em setores poluidores como a Aracruz, a Copel e a Vale, que não publicam o RSA e utilizam pesadamente o RA para divulgar suas informações ambientais) é de caráter mais generalista e superficial, o que dificulta a comparabilidade e a tomada de decisões baseadas nelas. Ficou claro neste estudo que as empresas pesquisadas utilizam o RA para evidenciar informações que sinalizam ao mercado que elas cumprem as suas obrigações ambientais e investem no meio ambiente de alguma forma, ou seja, elas deixam em segundo plano informações sobre a performance ambiental, litígios ou possíveis passivos que a empresa venha a ter no futuro por causa de problemas envolvendo o meio ambiente.

Existem diversas críticas quanto à credibilidade das informações ambientais prestadas pelas empresas em âmbito mundial, a principal delas decorre do fato de essas informações não serem, obrigatoriamente, auditadas, ou seja, as empresas podem divulgar o que quiserem. No decorrer da pesquisa, foi verificado que algumas 
das empresas pesquisadas que publicam o RSA seguem as orientações das agências especializadas em relatórios ambientais como a Global Reporting Initiativa - GRI, isso é um aspecto positivo, pois aumenta um pouco a confiabilidade das informações ambientais prestadas por essas empresas. Existem diversas sugestões para melhorar 0 nível de evidenciação ambiental das empresas. Uma delas é terminar com o aspecto voluntário dos relatórios ambientais e tornar a evidenciação ambiental obrigatória e auditada. Porém, existem poucos estudos empíricos que demonstrem que empresas que atuam em países regulamentados apresentam um melhor nível de evidenciação ambiental. Tendo em vista que essa prática, na maioria dos países, continua difundida de maneira voluntária (com exceção de alguns países como Holanda, Noruega, Suécia e outros) não se sabe ao certo quais benefícios a regulamentação irá trazer para o nível de evidenciação das empresas.

\section{REFERÊNCIAS}

AL-TUWAIJRI, Sulaiman A.; CHRISTENSEN, Theodore E.; HUGHES II, K. E. The relations among environmental disclosure, environmental performance, and economic performance: a simultaneous equations approach. Accounting, Organization and Society. v. 29, p. 447-471, 2004.

BELKAOUI, Ahmed. The Impact of the disclosure of the environmental effects of organizational behavior on the market. Financial Management (pré-1986), Winter 1976; 5,4; ABI/INFORM Global, p. 26.

BLACCONIERE, W. G; PATTEN, D. M. Environmental disclosures, regulatory costs, and changes in firm value. Journal of Accounting and Economics. p. 357-377, 1994.

BORBA, José Alonso ; ROVER, Suliani . Evidendenciação Ambiental: Uma Análise das Demonstrações Financeiras Padronizadas e dos Relatórios 20-F no Período de 2002 a 2004. Congresso Nacional de Excelência em Gestão, 3, 2006, Niterói-RJ. Anais... Niterói - RJ.

CALIXTO, Laura; LIMA, Marilene B.; BARBOSA, R. R. Disseminação de informações ambientais voluntárias: relatórios contábeis versus Internet. Revista de contabilidade e finanças da USP, 30 anos de doutorado, p. 84-95, junho 2007.

$\mathrm{CHO}$, Charles H; PATTEn, Dennis M. The role of environmental disclosures as tools of legitimacy: A research note. Accounting, Organization and Society. v. 32, p. 639647, 2007.

CLARKSON, Peter M; LI, Yue; RICHARDSON, Gordon D; VASVARI, Florin P. Revisiting the relation between environmental performance and environmental disclosure: An empirical analysis. Accounting, Organizations and Society. v. 33, p. 303-327, 2008.

COLLIS, Jill; HUSSEY, Roger. Pesquisa em administração: um guia prático para alunos de graduação e pós-graduação. 2 ed. Porto Alegre: Bookman, 2005. 
COSTA, R.S; MARION, J. C. A uniformidade na evidenciação das informações ambientais. Revista de contabilidade e finanças da USP, 43, p. 20-33, jan/abr, 2007.

DEEGAN, Craig. Environmental disclosures and share prices - a discussion about efforts to study this relationship. Accounting Forum, 28, p. 87-97, 2004.

; GORDON, B. A study of the environmental disclosures practices of Australian corporations. Accounting and Business Research. p. 187-199, 1996.

; RANKIN, Michaela. The materiality of environmental informations to users of annual reports. Accounting, Auditing \& Accountability journal. v. 10, 4, p. 562583, 1997.

DYE, R. A. Disclosure of non-proprietary information. Journal of Accounting Research, v. 8, p. 135-155, 1985.

EPSTEIN, Marc J; FREEDMAN, Martin. Social disclosure and the individual investor. Accounting, Auditing \& Accountability Journal. v. 7, 4, 1994.

FREEDMAN, M; WASLEY, C. The association between environmental performance and environmental disclosure in annual reports and 10K. Advances in Public Interest Accounting. v. 3, p. 183-193, 1990.

; JAGGI, M. An analysis of the association between pollution disclosure and economic performance. Accounting, Auditing \& Accountability Journal. v. 1, 2, p. 43-58, 1988.

; PATTEN, Dennis M. Evidence on the pernicious effect of financial report environmental disclosure. Accounting Forum, 28, p. 27-41, 2004.

GRAY, Rob; BEBBINGTON, Jan. Accounting for the Environment. 2 ed. Londres: Sage, 2001.

GRAY, Robert; OWEN, Dave; ADAMS, Carol. Accounting \& Accountability: Changes and Challenges in Corporate Social and Environmental Reporting. Londres: Prentice Hall Europe, 1996.

HUGHES, Susan B.; ANDERSON, Allison; GOLDEN, Sarah. Corporate environmental disclosures: are they useful in determining environmental performance? Journal of Accounting and Public Policy. 20, p. 217-240, 2001.

INGRAM R. W.; FRAZIER K. Environmental Performance and corporate disclosure. Journal of Accounting Research, v. 18, 2, p. 614-622, 1980.

INGRAM, R.W. Investigation of the Information Content of Certain Social Responsibility Disclosure. Journal of Accounting Research, v.16, 2, p. 270-85, 1978.

LIMA, Diana Vaz de; VIEGAS, Waldyr. Tratamento contábil e evidenciação das externalidades ecológicas. Revista de contabilidade e finanças da USP, 30, 2002.

LORRAINE, N. H. J; COLLISON, D. J.; POWER, D. M. An analysis of the stock market 
impact of environmental performance information. Accounting Forum, 28, p. 7-26, 2004.

MILNE, Markus J.; ADLER, Ralph W. Exploring the reliability of social and environmental disclosures content analysis. Accounting, Auditing \& Accountability Journal, v. 12, 2, p. 237-256, 1999.

MURRAY, Alan; SINCLAIR, Donald; Power, David; GRAY, Robert. Do financial markets care about social and environmental disclosure? Further evidence and exploration from the UK. Accounting, Auditing \& Accountability Journal, v. 19, 2, p. 228-255, 2006.

NOSSA, Valcemiro. Disclosure ambiental: uma análise do conteúdo dos relatórios ambientais de empresas do setor de papel e celulose em nível internacional. 2002. 246f. Tese (Doutorado em Ciências Contábeis) Programa de Pós-Graduação em Controladoria e Contabilidade, Universidade de São Paulo, São Paulo, 2002.

PATTEN, Dennis $M$. The relation between environmental performance and environmental disclosure: a research note. Accounting, Organization and Society, v. 27 , p. 763-773, 2002.

. The market reaction to social responsibility disclosures: the case of the $\overline{S u l l i v a n}$ principles signings. Accounting, Organizations and Society, v. 15, 6, p.575587, 1990.

RIBEIRO, Maisa de Souza; MARTINS Eliseu. A informação como instrumento de contribuição da contabilidade para a compatibilização no desenvolvimento econômico e a preservação do meio ambiente. Cadernos de estudos FIPECAFI, 9, outubro, 1993.

; SOUZA, V. R; Aplicação da contabilidade ambiental na indústria madeireira. Revista de contabilidade e finanças da USP, 35, p. 54-67, mai/ago, 2004.

ROVER, Suliane; ALVES, Jorge Luiz; BORBA, José Alonso. A evidenciação do passivo ambiental: quantificando o desconhecido. Revista contemporânea em contabilidade, v. 1, 5, ano 03, p. 41-58, 2006.

SHANE, P.; SPICER, B. Market Response to Environmental Information Produced Outside the Firm. The Accounting Review, v. 58, 3, p. 521-38, 1983.

TINOCO, João. Balanço social e contabilidade no Brasil. Caderno de Estudos da USP. 9, p. 1- 4, 1993.

VERRECCHIA, R. Discretionary disclosure. Journal of accounting and economics, v. 5, p. 179 - 194, 1983.

WISEMAN, Joane. An evaluation of environmental disclosures made in corporate annual reports. Accounting, Organization and Society, v.7, 1, p. 553-563, 1982. 


\title{
ENDEREÇO DOS AUTORES:
}

\author{
Alex Mussoi \\ Universidade de São Paulo \\ Programa de pós-graduação em controladoria e contabilidade da FEA \\ Rua Dr. Arnaldo da Silva Ferreira, 405 - Ipanema. \\ Porto Alegre, RS - Brasil \\ 91760-240 \\ Hans Michael Van Bellen \\ Universidade Federal de Santa Catarina \\ Centro Tecnológico, Departamento de Engenharia do Conhecimento. \\ Campus Universitário - Trindade \\ Florianopolis, SC - Brasil \\ 88040-900
}

